2. Subramanian VA, Patel NU. Transabdominal minimally invasive direct coronary artery bypass grafting (MIDCAB). Eur J Cardiothorac Surg. 2000;17:485-7.

3. Coulson AS, Glasgow EF, Bonatti J. Minimally invasive subclavian/ axillary artery to coronary artery bypass (SAXCAB): review and classification. Heart Surg Forum. 2001;4:13-25.
4. Yaryura R, Vardhan R, Springer AJ, Cooley DA. A 66-year-old man with severe angina and previous coronary artery bypass. Lancet. 1997; 349:396.

5. Ohtsuka T, Suematsu Y, Kubota H, Takamoto S, Makuuchi M. Salvage of right gastroepiploic artery graft before pancreatoduodenectomy. J Thorac Cardiovasc Surg. 2001;121:1013-4.

\title{
Orthotopic mitral valve replacement with autologous pulmonary valve in a porcine model
}

\author{
Khanh Nguyen, MD, ${ }^{a}$ Justus T. Strauch, MD, ${ }^{a}$ Shubhika Srivastava, MD, ${ }^{\mathrm{b}}$ Alexander Lauten, MS, ${ }^{\text {a }}$ \\ Peter Haldenwang, MS, ${ }^{a}$ Ning Zhang, MD, ${ }^{a}$ Susan Vlahakis, CCP, ${ }^{a}$ and David H. Adams, MD, ${ }^{a}$ New York, NY
}

$\mathrm{M}$ itral valve replacement in children continues to be a challenge because of the unavailability of an ideal prosthesis. Although most patients can have a successful palliation with repair, some need valve replacement.

In the 1960s, Willman and colleagues ${ }^{1}$ made early attempts to place a semilunar valve in the orthotopic mitral position in dogs. Subsequent work involved implantation of a semilunar valve homograft or autograft in a supra-annular location in a special configuration called a top hat. $^{2}$ However, the limitation of growth inherent in this approach makes it less attractive in the pediatric population.

We have begun to investigate the possibility of implanting the pulmonary valve orthotopically in the mitral position (Figures 1 and 2). This approach retains the freedom from anticoagulation and the durability that make the top hat operation attractive but also permits growth, because there is no physical constraint from the top hat supporting tube. This report presents preliminary data in a short-term study in a porcine model on the feasibility of orthotopic mitral valve replacement with an autologous pulmonary valve.

\section{Materials and Methods}

All animals received humane care in compliance with the guidelines of "Principles of Laboratory Animal Care," formulated by the

From the Departments of Cardiothoracic Surgery ${ }^{\mathrm{a}}$ and Pediatrics, ${ }^{\mathrm{b}}$ Mount Sinai Medical Center, New York, NY.

Received for publication July 11, 2003; accepted for publication Nov 17, 2003.

Address for reprints: Khanh Nguyen, MD, Pediatric Cardiac Surgery, Department of Cardiothoracic Surgery, Mount Sinai Medical Center, Box 1028, 1190 Fifth Ave, New York, NY 10029 (E-mail: Khanh.Nguyen@mountsinai.org).

J Thorac Cardiovasc Surg 2004;127:1527-9

$0022-5223 / \$ 30.00$

Copyright $(9) 2004$ by The American Association for Thoracic Surgery

doi:10.1016/j.jtcvs.2003.11.055
National Society for Medical Research, and "Guide for the Care and Use of Laboratory Animals" (http://www.nap.edu/catalog/ $5140 . \mathrm{html})$. The protocol for this experiment was approved by our institutional animal care and use committee.

Eight juvenile pigs, weighing from 25 to $35 \mathrm{~kg}$, were studied. After intramuscular treatment with ketamine $(15 \mathrm{mg} / \mathrm{kg})$ and atropine $(0.03 \mathrm{mg} / \mathrm{kg})$, the animals were anesthetized by intravenous injection of sodium thiopental $(20 \mathrm{mg} / \mathrm{kg})$ and underwent endotracheal intubation. The subjects were ventilated mechanically with an inspired oxygen fraction of 50\%, and isoflurane at $1 \%$ to $2 \%$ was used to maintain anesthesia. Paralysis was achieved with intravenous pancuronium $(0.1 \mathrm{mg} / \mathrm{kg})$. An arterial line was placed in the right brachial artery for pressure monitoring and blood sampling $\left(\mathrm{pH}, \mathrm{Po}_{2}, \mathrm{PCO}_{2}\right.$, oxygen saturation, base excess, hematocrit, hemoglobin, glucose, and lactate, Ciba Corning 865 Blood Gas Analyzer; Chiron Diagnostic, Norwood, Mass). A left atrial line was inserted for monitoring of left atrial pressure after separation from cardiopulmonary bypass (CPB). The subjects were given inotropic support (including dobutamine at 10 $\mathrm{mg} /[\mathrm{kg} \cdot \mathrm{min}]$ and titrated with epinephrine at $100-200 \mathrm{ng} /[\mathrm{kg}$. min]) to maintain a normal mean systemic pressure of 40 to 50 $\mathrm{mm} \mathrm{Hg}$.

Surgical technique. The heart was exposed by a left thoracotomy through the 5th intercostal space. The subject was placed on $\mathrm{CPB}$, and hypothermia was induced. During cooling, and with the heart beating, the pulmonary artery was harvested by transecting it proximal to the bifurcation and disconnecting the infundibulum from the right ventricle. The aorta was crossclamped, and blood cardioplegia was given though the aortic root. The left atrium was opened, and the native mitral valve was left in situ. The pulmonary artery was prepared, the wall of one sinus was resected, and the resected sinus was oriented toward the left ventricular outflow tract. The pulmonary arterial end of the graft was anchored to the tip of the papillary muscles at four sites (Figure 3) with pledgeted 4-0 polypropylene sutures. A continuous running mattress anastomosis of the right ventricular end of the graft with 4-0 polypropylene suture was carried out 1 to $2 \mathrm{~mm}$ below the pulmonary valve annulus, plicating through the mitral leaflets close to the hinge area of the native mitral valve (Figure 1). A valved conduit (Shelhigh, Inc, Union, NJ) was placed in the right ventricular outflow tract, and the subject was removed from CPB. A trans- 


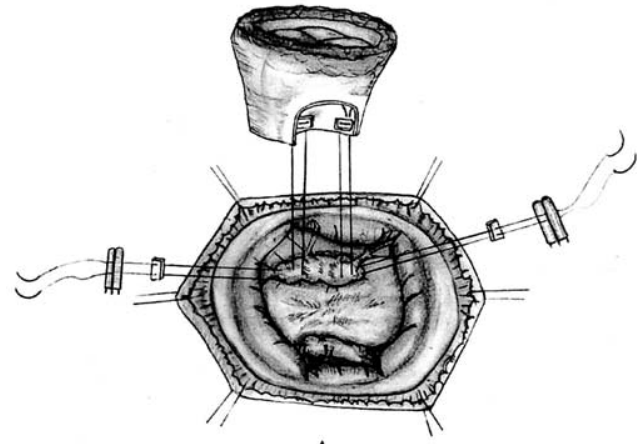

A

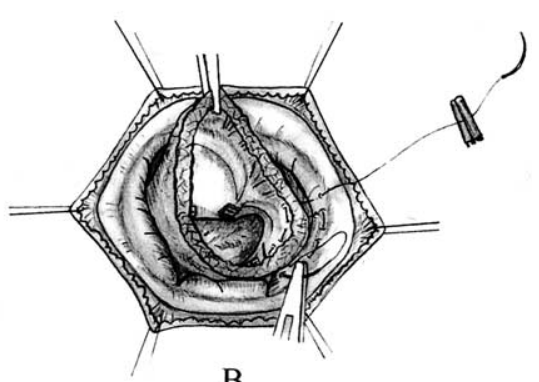

B

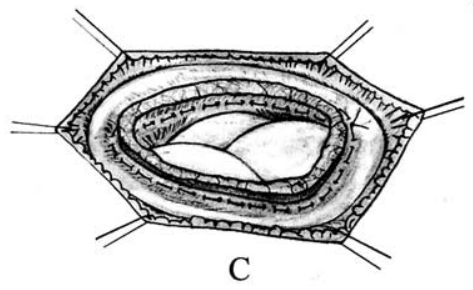

Figure 1. A, Pulmonary autograft is implanted in orthotopic mitral position. Pulmonary artery end of autograft is anchored to tips of papillary muscles. B, Ventricular end of autograft is anastomosed to hinge area of native mitral valve. C, Autologous pulmonary valve in orthotopic mitral position.
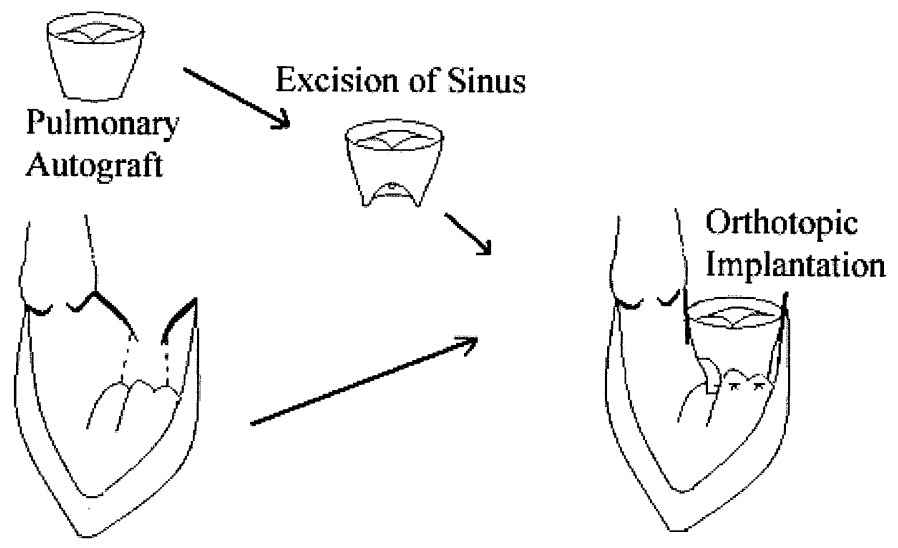

Figure 2. Pulmonary autograft with one sinus excised is implanted orthotopically in mitral position. Excised sinus is facing left ventricular outflow tract. Note that native mitral valve is left in situ.
Left Ventricular Outflow

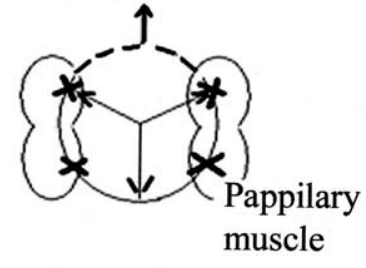

4 point anchoring

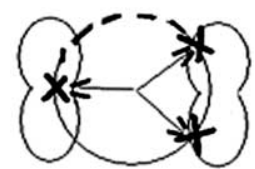

Alternate Method 3 point anchoring

\section{IValve commissure \\ $\times \quad$ Anchoring suture \\ - - Excised sinus}

Figure 3. Two possible configurations for anchoring pulmonary end of autograft to papillary muscles.

TABLE 1. Subject data

\begin{tabular}{|c|c|c|c|c|c|c|}
\hline \multirow[b]{2}{*}{ Subject } & \multicolumn{2}{|c|}{ Transesophageal echocardiography } & \multirow[b]{2}{*}{$\begin{array}{l}\text { Left atrial pressure } \\
\text { (mm Hg, direct) }\end{array}$} & \multirow[b]{2}{*}{$\begin{array}{c}\text { Crossclamp } \\
\text { time (min) }\end{array}$} & \multirow[b]{2}{*}{$\begin{array}{l}\text { CPB time } \\
\text { (min) }\end{array}$} & \multirow[b]{2}{*}{ Comment } \\
\hline & $\begin{array}{c}\text { Mitral } \\
\text { regurgitation }\end{array}$ & $\begin{array}{c}\text { Mean autograft } \\
\text { gradient }(\mathrm{mm} \mathrm{Hg})\end{array}$ & & & & \\
\hline 1 & Mild & $-^{*}$ & $9-11$ & 120 & 182 & Killed after weaning from CPB \\
\hline 2 & Mild & 5.7 & 10 & 80 & 125 & Killed after weaning from CPB \\
\hline 3 & Mild to moderate & 1.8 & 12 & 90 & 130 & Killed after weaning from CPB \\
\hline 4 & Moderate & 2.8 & $10-14$ & 75 & 110 & Repair left anterior descending \\
\hline 5 & Mild & $-^{*}$ & $8-12$ & 65 & 120 & Poor left ventricular function \\
\hline 6 & Mild & 5.7 & $5-6$ & 45 & 90 & $\begin{array}{l}\text { Pulmonary valve from donor; survived to day } \\
\text { 3, dehisced free wall anchoring suture }\end{array}$ \\
\hline 7 & Trivial to mild & 5.5 & $10-15$ & 38 & 125 & Mitral valve plicated \\
\hline 8 & Mild & 6 & $8-10$ & 38 & 123 & \\
\hline
\end{tabular}

*Gradients could not be determined because of technical difficulty. 
esophageal probe was inserted, and the function of the valve was examined. Because of unexpected availability of a fresh donor porcine valve, 1 subject (subject 6) had a homograft rather than autograft implanted.

\section{Results}

All subjects were successfully separated from CPB and had normal systemic pressures immediately after weaning. All but 1 subject (subject 6, who survived for 3 days) died several hours after extubation, during the night after the procedure. The long-term survivor had implantation of a fresh porcine pulmonary valve from a donor. This valve was found to have a dehisced distal free wall suture that appeared to cause mitral inflow obstruction.

The postprocedure hematocrits of the subject were in the mid 20s. Continuous wave Doppler interrogation of the left ventricular outflow tracts to measure flow acceleration were available for the last 2 subjects, and they were about $1 \mathrm{~m} / \mathrm{s}$. The results of transesophageal echocardiography, left atrial pressures, mean gradient across the autograft, and data on CPB are shown in Table 1.

\section{Discussion}

In the only report of a similar procedure, by Willman and colleagues $^{1}$ in 1961, a semilunar valve, albeit an aortic homograft, was inserted in the mitral orthotopic location in a dog. The subsequent use of pulmonary valve to replace the mitral valve has involved mainly its use in the top hat configuration, with the graft usually mounted inside a prosthetic tube for support. ${ }^{2}$ This technique, however, limits growth when used in pediatric patients.

In this preliminary study it was feasible to insert a pulmonary valve in the orthotopic mitral position with reproducible results. Transesophageal echocardiography showed good flow dynamics through the graft (Figure 4). Distal anchoring sutures are placed near the pulmonary commissures, and the excision of one of the sinuses ensures a wide-open outflow pathway.

It has previously been observed that the lungs of pigs are quite delicate, and CPB may have a deleterious impact on their function. $^{3,4}$ As noted, most subjects were hemodynamically stable during mechanical ventilation. The next phase of our study will be directed toward generating a survival model to look at growth potential and long-term function. We hope that orthotopic mitral valve replacement with a pulmonary autograft proves to be a solution for children with mitral valve disease when the valve

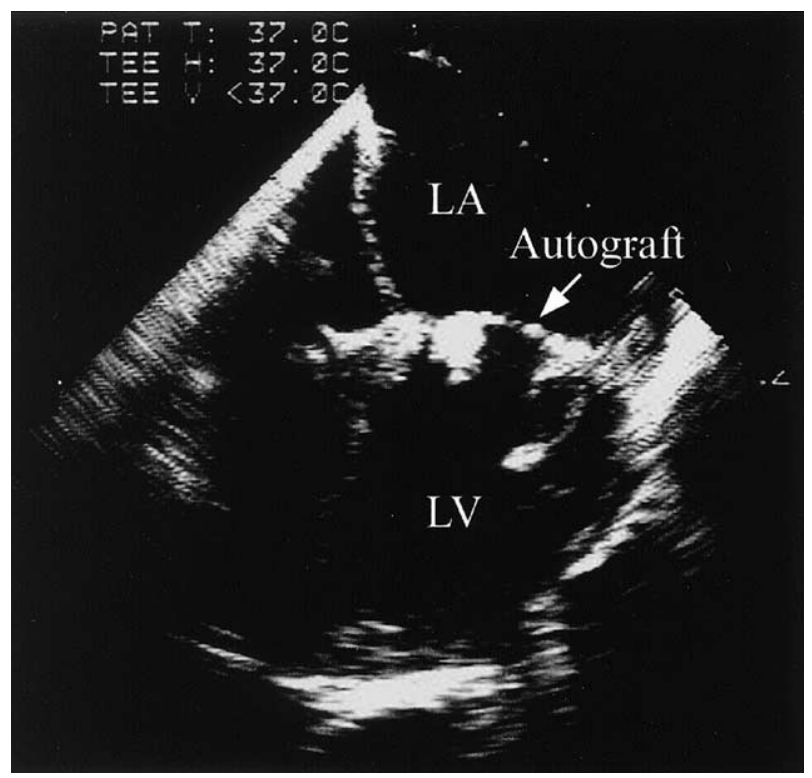

Figure 4. Transesophageal echocardiogram of pulmonary autograft (arrow) in orthotopic mitral position. $L A$, Left atrium; $L V$, left ventricle.

cannot be repaired, providing an alternative that does not require anticoagulation, is durable, and has a potential for growth.

\section{References}

1. Willman LV, Zafiracopoulos P, Hanlon CR. Replacement of the mitral valve with homograft aortic valve. In: Merendino KA, editor. Prosthetic valves for cardiac surgery. Springfield (IL): Charles C Thomas; 1961. p. 142-8.

2. Ross DN, Kabbani S. Mitral valve replacement with a pulmonary autograft: the mitral top hat. J Heart Valve Dis. 1997;6:542-5.

3. Serraf A, Sellak H, Herve P, Bonnet N, Robotin M, Detruit H, et al. Vascular endothelium viability and function after total cardiopulmonary bypass in neonatal piglets. Am J Respir Crit Care Med. 1999;159:54451.

4. Chai PJ, Williamson JA, Lodge AJ, Daggett CW, Scarborough JE, Meliones JN, et al. Effects of ischemia on pulmonary dysfunction after cardiopulmonary bypass. Ann Thorac Surg. 1999;67:731-5. 